\title{
Testing the acceleration spectra given by China and USA seismic codes based on en- ergy supply in near-fault region*
}

\author{
JIANG Hui ${ }^{*}$ (江 辉) ZHU Xi (朱 目希) \\ School of Civil Engineering, Beijing Jiaotong University, Beijing 100044, China
}

\begin{abstract}
For near-fault ground motion, there should be a remarkable impulsive energy supply. Therefore, it is essential to check the validity of actual seismic design codes with energy balance concept. Based on the relationship between the spectrum velocity and the input energy equivalent velocity with $5 \%$ damping ratio, the input energy spectra compatible with main China and USA seismic codes were derived, and the accuracy and applicability were verified by using near-fault records. The recommended energy input design spectrum (EIDS) applicable to the distance of $0 \sim 15 \mathrm{~km}$ from fault was introduced to check the validity of modern seismic codes. Comparison tests show that the GB50011-2001 Code of China can just match the energy effect of near-fault ground motion to a certain extent only under seldom occurred earthquake with fortification intensity of 9 degree for site soil of III and IV, indicating that the impact of near-fault effect has not been embodied in the current code acceleration spectrum. In order to make the design spectrum be applicable to near-fault region, it is necessary to adjust the spectrum platform parameters. On the contrary, for distinct fault distance and site soil, the UBC97 Code of USA can match well with the energy supply of near-fault ground motion except for the site soil of hard rock $\left(S_{\mathrm{A}}\right)$. Accordingly, correctness of the formula derivation in this paper is certified.
\end{abstract}

Key words: near-fault ground motion; energy balance; seismic design code; spectrum velocity amplification factor

CLC number: P315.9 Document code: A

\section{Introduction}

Since the last two decades, especially after the 1999 Chi-Chi earthquake in the region of Taiwan, earthquake features and seismic damage characteristics near the active fault zones have caused comprehensive attention. One of the notable features of near-fault ground motion (also known as near-field ground motion) is the massive energy supply for impulse-type velocity input with long-duration (Somerville et al, 1997), which asks for higher energy dissipation capacity for civil buildings and bridges (Chou and Uang, 2000; GONG et al, 2003).

Due to this special feature of near-fault ground motion, the Unified Building Code of 1997 version (UBC97) (International Council of Building Officials, 1997) was issued after three years of the 1994 Northridge earthquake, which was the first code to take into account theoretically the

\footnotetext{
* Received 2007-12-10; accepted in revised form 2008-08-13.

Foundation item: National Natural Science Foundation of China (50278002, 50578007); Specialized Research Fund for the Doctoral Program of Higher Education (200040004025)

^Author for correspondence: jianghui@bjtu.edu.cn
} 
near-fault effect by introduction of near-fault factor, for the aim to adjust the standard acceleration spectrum. Particularly after the 1995 Kobe earthquake and the 1999 Chi-Chi earthquake, Japan and Chinese Taiwan have amended the original seismic design code, in order to strengthen the fortification measures and capacity for structures close to near-field zones. However, the current code for seismic design of buildings of China (GB50011-2001) (Ministry of Construction of the People's Republic of China, 2001) takes the measure of smallest giving-way distance from active fault to deal with near-fault effect on the structure, and has not resolved such problem from the point of view of design earthquake level, which need further research. Especially since the outbreak of the 1999 Turkish Kocaelia earthquake, Duzce earthquake, including the 1999 Chi-Chi earthquake, a considerable number of records near the active faults have been accumulated; it is time to be re-awareness of the applicability of seismic codes of GB50011-2001 and UBC97 from the new record database.

In this paper, based on the collection of earthquake records close to faults all around the world, the equivalent energy compatible with code acceleration spectrum was derived by the introduction of spectrum velocity amplification factor, and the range of effective period for this transformation formula was extracted. Finally, the applicability of these two codes was checked and discussed.

\section{The seismic design provisions for structures close to faults by codes of GB50011-2001 and UBC97}

\subsection{The code for seismic design of buildings of China (GB50011-2001)}

According to the code for seismic design of buildings of China (GB50011-2001), the measure of smallest giving-way distance was take to deal with the seismic fortification requirement for buildings of types $B$ and $C$, and specialized research is asked to deal with near-fault problem for buildings of type $A$ (Table 1). It indicates the code has recognized the potential damage ability of fault, but still lacks effective methods such as specified design acceleration spectrum for use in near-field zones. However, some of China's major cities such as Chengdu, Urumqi, Lanzhou and Xining are located at the near-fault regions of latent earthquakes, and how to conduct reasonable seismic fortification and seismic design has become prominent problems.

Table1 The shortest giving-way distance (m) from active fault after the GB50011-2001 Code

\begin{tabular}{ccccc}
\hline \multirow{2}{*}{ Fortification intensity } & \multicolumn{4}{c}{ Building seismic fortification categories } \\
\cline { 2 - 5 } & $A$ & $B$ & $C$ & $D$ \\
\hline 8 & Specialized research & 300 & 200 & - \\
9 & Specialized research & 500 & 300 & - \\
\hline
\end{tabular}

\subsection{UBC97 Code of USA}

The UBC97 Code is the first to consider explicitly the near-fault effect by introduction of near-fault factor $\left(N_{a}, N_{v}\right)$. With 10 percent probability of exceedance, the whole United States is divided into five seismic zones, and the corresponding effective peak accelerations are $0.075 \mathrm{~g}, 0.15 \mathrm{~g}, 0.20 \mathrm{~g}, 0.30 \mathrm{~g}, 0.40 \mathrm{~g}\left(\mathrm{~g}=9.8 \mathrm{~m} / \mathrm{s}^{2}\right)$, respectively. The region which needs to take into account near-fault effect is the zone 4, which is mainly in California, the west coast of USA. According to moment magnitude $\left(M_{\mathrm{W}}\right)$ and slip ratio of active fault per year $\left(S_{R}\right)$, the faults are divided to three categories as $A, B$ and $C$. And for zone 4, near-fault factor $N_{a}$ and $N_{v}$ (Table 2) is 
given based on the two indicators of fault distance and fault type. By the introduction of $N_{a}$ and $N_{v}$, the specified design spectrum applicable to near-fault regions can be obtained from standard spectrum. Figure 1 gives the comparison of standard design spectrum and special near-fault spectrum of UBC97 Code, in which $C_{\mathrm{a}}$ and $C_{\mathrm{v}}$ are ground response factors. It can be seen that there is obvious difference between these two spectra during long period extent, which is an adjustment of the standard spectrum by the role of near-fault factor $N_{a}$ and $N_{v}$. A second platform with height of $0.8 C_{\mathrm{a}}$ ex-

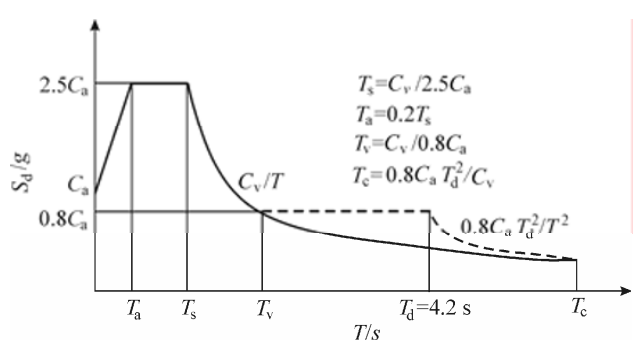

Figure 1 Comparison of standard spectrum (solid line) and near-fault spectrum (dashed line) of UBC97 Code (damping ratio $\xi=5 \%)$ ists for the near-fault design spectrum; however, the standard spectrum attenuates with a slope of $C_{\mathrm{v}} / T$ in the corresponding period range, which embodies the stronger earthquake supply for regions close to active faults. But it should be noted that the near-fault factor $\left(N_{a}, N_{v}\right)$ of UBC97 Code was obtained mainly from earthquakes with moment magnitude $\left(M_{\mathrm{W}}\right)$ less than 7.0, and the quantity of records used at that time was limited. It is necessary to check the suitability from new records gained in recent years.

Table 2 Near-fault factor $N_{a}$ and $N_{v}$ by UBC97 Code

\begin{tabular}{|c|c|c|c|c|c|c|c|c|c|}
\hline \multirow{3}{*}{ Type of fault } & \multirow{3}{*}{ Source description } & \multicolumn{8}{|c|}{ Fault distance } \\
\hline & & \multicolumn{2}{|c|}{$\leq 2 \mathrm{~km}$} & \multicolumn{2}{|c|}{$5 \mathrm{~km}$} & \multicolumn{2}{|c|}{$10 \mathrm{~km}$} & \multicolumn{2}{|c|}{$15 \mathrm{~km}$} \\
\hline & & $N_{\mathrm{a}}$ & $N_{\mathrm{v}}$ & $N_{\mathrm{a}}$ & $N_{\mathrm{v}}$ & $N_{\mathrm{a}}$ & $N_{\mathrm{v}}$ & $N_{\mathrm{a}}$ & $N_{\mathrm{v}}$ \\
\hline$A$ & $M_{\mathrm{W}} \geq 7.0, S_{R} \geq 5.0$ & 1.5 & 2.0 & 1.2 & 1.6 & 1.0 & 1.2 & 1.0 & 1.0 \\
\hline$B$ & Between $A$ and $C$ & 1.3 & 1.6 & 1.0 & 1.2 & 1.0 & 1.0 & 1.0 & 1.0 \\
\hline C & $M_{\mathrm{W}} \leq 6.5, S_{R} \leq 2.0$ & 1.0 & 1.0 & 1.0 & 1.0 & 1.0 & 1.0 & 1.0 & 1.0 \\
\hline
\end{tabular}

\section{Energy spectrum compatible with code acceleration spectrum and its effective period range}

\subsection{Database of earthquake records}

Because the seismic damage of the structure is directly related to its distance from fault, then fault projection distance should be selected as one of the main qualifications for selecting earthquake records. The three criterions are as follows:

(a) Fault projection distance: $d_{\mathrm{f}} \leq 15 \mathrm{~km}$; (b) Peak ground acceleration: $a_{\mathrm{PG}} \geq 0.05 \mathrm{~g}$ $\left(\mathrm{g}=9.8 \mathrm{~m} / \mathrm{s}^{2}\right)$; (c) Moment magnitude: $M_{\mathrm{W}} \geq 5.0$

According to the above criteria, a total of 214 horizontal records from 16 major earthquakes (Table 3) were selected (JIANG, 2007). These records are mainly from the earthquakes of USA and the 1999 Chi-Chi earthquake, but the classification criterions of site soil are not the same for the USA Geological Survey (USGS) and Taiwan's CWB. And even some near-fault records have no detailed site soil information, so it's difficult to classify these records accurately in response to the current seismic design code. Therefore the classification criterions of site soil for USGS and CWB have to be combined: the site soil of $S_{A}, S_{B}$ of USGS and rock soil of CWB are taken as site soil of $S_{1}$; the site soil of $S_{C}$ of USGS and median soil of CWB are taken as site soil of $S_{2}$; the site 
Table 3 Earthquakes selected for analysis

\begin{tabular}{clccc}
\hline No. & Earthquake & Date & $M_{\mathrm{W}}$ & $\begin{array}{c}\text { Amount of } \\
\text { records }\end{array}$ \\
\hline 1 & Chi-Chi & $1999-09-20$ & 7.6 & 78 \\
2 & Coyote Lake & $1979-08-06$ & 5.7 & 10 \\
3 & Hollister & $1974-11-28$ & 5.2 & 7 \\
4 & Kocaeli & $1999-08-17$ & 7.4 & 7 \\
5 & Loma Prieta & $1989-10-18$ & 6.9 & 14 \\
6 & Northridge & $1994-01-17$ & 6.7 & 26 \\
7 & San Francisco & $1957-03-22$ & 5.3 & 2 \\
8 & Cape Mendocino & $1992-04-02$ & 7.1 & 4 \\
9 & Duzce, Turkey & $1999-11-12$ & 7.1 & 4 \\
10 & Imperial Valley & $1979-10-15$ & 6.5 & 40 \\
11 & Livermore & $1980-01-27$ & 5.4 & 3 \\
12 & Lytle Creek & $1970-09-12$ & 5.4 & 2 \\
13 & Landers & $1992-06-28$ & 7.3 & 2 \\
14 & Parkfield & $1966-06-28$ & 6.1 & 5 \\
15 & Kobe & $1995-01-16$ & 6.9 & 8 \\
16 & Westmorland & $1981-04-26$ & 5.8 & 2 \\
\hline
\end{tabular}

Table 4 Earthquake records grouped after soil type and fault distance

\begin{tabular}{ccccc}
\hline \multirow{2}{*}{ Site soil type } & \multicolumn{3}{c}{ Amount of record grouped } & \multirow{2}{*}{ Total } \\
\cline { 2 - 4 } & $0 \sim 5 \mathrm{~km}$ & $5 \sim 10 \mathrm{~km}$ & $10 \sim 15 \mathrm{~km}$ & \\
\hline$S_{1}$ & $29 / 15$ & $22 / 11$ & $32 / 17$ & $83 / 43$ \\
$S_{2}$ & $16 / 8$ & $18 / 9$ & $10 / 5$ & $44 / 22$ \\
$S_{3}$ & $30 / 15$ & $27 / 14$ & $30 / 15$ & $87 / 44$ \\
\hline
\end{tabular}

Note: Before the "/" is the number of earthquake records, and after the "/" is the number of record groups. soil of $S_{D}$ of USGS and soft soil of CWB are taken as site soil of $S_{3}$ in this paper. Meanwhile, in order to consider the impact of fault distance, all the 214 records are divided into three categories in accordance with the fault distance from $0 \sim 5 \mathrm{~km}, 5 \sim 10$ $\mathrm{km}$ to $10 \sim 15 \mathrm{~km}$. And the records for three distance range are respectively 29,22 , and 32 for site soil of $S_{1} ; 16,18$ and 10 for site soil of $S_{2} ; 30,27$ and 30 for site soil of $S_{3}$ (Table 4).

\subsection{Derivation of equivalent energy from code acceleration spectrum}

In order to test the code response spectrum from energy balance concept, it is needed to seek the relationship between spectrum acceleration and equivalent velocity of input energy. Based on the spectrum velocity amplification factor (JIANG, 2007), a procedure to derive equivalent velocity of input energy compatible with the code design spectrum was developed as follows

1) From the integral analysis of SDOF differential equation, it can be drawn that when damping ratio of the structure is less than 0.10 , the influence of damping could be ignored. And then the following relationship exists between absolute spectrum acceleration $a_{\mathrm{s}}$ and pseudo spectrum velocity $v_{\mathrm{ps}}$ :

$$
a_{\mathrm{s}}(T, \xi)=\omega v_{\mathrm{ps}}(T, \xi) \Rightarrow v_{\mathrm{ps}}(T, \xi)=a_{\mathrm{s}}(T, \xi) / \omega
$$

In equation (1), $T$ is natural vibration period of the structure; $\xi$ is damping ratio of the structure; $\omega$ is natural vibration frequency of the structure. And thus the pseudo spectrum velocity $v_{\mathrm{ps}}$ could be obtained.

2) According to the research of Hudson (1962), with the exception of particularly long period, there is minute difference between relative spectrum velocity $v_{\mathrm{s}}$ and pseudo spectrum velocity $v_{\mathrm{ps}}$, and then the following equation exists:

$$
v_{\mathrm{ps}}(T, \xi) \cong v_{\mathrm{s}}(T, \xi) \Rightarrow v_{\mathrm{s}}(T, \xi)=a_{\mathrm{s}}(T, \xi) / \omega
$$

3) When damping ratio $\xi$ is $5 \%$, input energy equivalent velocity $v_{\mathrm{e}}$ can be calculated from spectrum velocity $v_{\mathrm{s}}$, by the introduction of spectrum velocity amplification factor $\Omega_{v_{s}}$ (JIANG, 2007):

$$
v_{\mathrm{e}}=v_{\mathrm{s}} \cdot\left(1 / \Omega_{v_{s}}\right) \Rightarrow v_{\mathrm{e}}=\left(a_{\mathrm{s}}(T, \xi) / \omega\right) \cdot\left(1 / \Omega_{v_{s}}\right)
$$

In which, the expression of $\Omega_{v_{s}}$ is as follows:

$$
\Omega_{v_{s}}= \begin{cases}a_{1} T / T_{1} & 0<T \leq T_{1} \\ a_{1}+a_{2}\left(T-T_{1}\right) & T_{1}<T<5.0 \mathrm{~s}\end{cases}
$$


In equation (4), $T_{1}$ is the control period of turning-point; $a_{1}$ and $a_{2}$ are regression parameters, which is given by Table 5. Once the parameters in equation (4) are determined, then the input energy equivalent velocity $v_{\mathrm{e}}$ compatible with the code design acceleration spectrum can be calculated by equation (3).

\subsection{Extraction of the effective period range for the equivalent formula}

Just as Hudson has ever pointed out, equation (2) comes into existence only for a certain range except for very long period, but Hudson did not give a clear quantitative scope of effective period. It is necessary to study the applicable range of this formula, which is the core foundation for calculation of energy equivalent velocity from spectrum acceleration. For the design acceleration spectra of GB50011-2001 Code and UBC97 Code, there exists a minimum requirement of shear capacity for long period structure, and thus a second platform was specified in the design spectra of these codes. However, when the acceleration spectrum value of this platform was transferred by equation (2), the resulted pseudo spectrum velocity would increase rapidly as the augment of structure period, which is obviously irrational.

On obtaining the displacement spectrum by transformation from the corresponding acceleration spectrum, NI (2001) found that the spectrum displacement increased rapidly with structural period under long-period range for high-damping structure, and then he advised to use the peak ground displacement $\left(d_{\mathrm{PG}}\right)$ as the upper limit, but he did not discuss the reasons of this illogical phenomena. In order to solve this problem, Eurocode8 Code (European Committee for Standardization, 2003) limited the spectrum displacement for long period structure, and the spectrum value of the second platform was limited to be no larger than the equivalent maximum ground motion displacement $d_{\mathrm{g}}$ :

$$
d_{g}=0.025 a_{\mathrm{g}} \cdot S \cdot T_{C} \cdot T_{D}
$$

In equation (5), $a_{\mathrm{g}}$ is the design earthquake acceleration; $S$ is the soil factor; $T_{C}$ is the upper limit of the period of the constant spectral acceleration branch; $T_{D}$ is the value defining the beginning of the constant displacement response range.

For comparison, Figure 2 gives the time history of pseudo spectrum velocity and spectrum velocity of two earthquake records (Table 6), and $t_{\mathrm{d}}$ in Table 6 is effective duration of strong earthquake within 95\% intensity domain (Trifunac and Brady, 1975). It can be seen that the two curves meet well when the period $T$ is less than $2.4 \mathrm{~s}$, and the difference enlarges with the increment of structural period, which means equation (5) is correct only under a certain range of period.

In order to explore the effective period range for equation (2), the 214 records were divided into three groups according to the types of site soil, for the aim of calculation of the ratio of pseudo spectrum velocity over spectrum velocity. The range of effective period was confirmed in accordance with the 80 percent of confidence interval $(0.8 \sim 1.2)$ of average ratio. It can be seen

Table 6 Two near-fault earthquake records used for testing conformation

\begin{tabular}{llccccccc}
\hline \multicolumn{1}{c}{ Station } & \multicolumn{1}{c}{ Events } & $M_{\mathrm{W}}$ & $d_{\mathrm{f}} / \mathrm{km}$ & $a_{\mathrm{pg}} / \mathrm{cm} \cdot \mathrm{s}^{-2}$ & $v_{\mathrm{pg}} / \mathrm{cm} \cdot \mathrm{s}^{-1}$ & Duration $t_{\mathrm{d}} / \mathrm{s}$ & $T_{\mathrm{g}} / \mathrm{s}$ & $T_{\mathrm{p}} / \mathrm{s}$ \\
\hline Pacoima Dam & 1971 San Fernando & 6.7 & 0 & 1201.5 & 112.5 & 7.05 & 0.6 & 1.8 \\
Rinaldi & 1994 Northridge & 6.7 & 0 & 821.2 & 166.1 & 7.04 & 1.3 & 1.7 \\
\hline
\end{tabular}



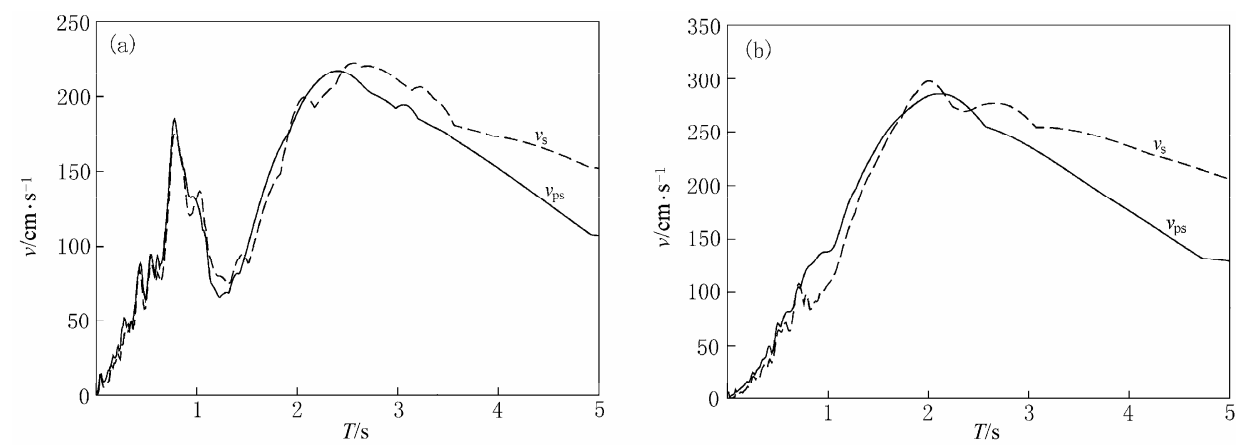

Figure 2 Comparison between pseudo spectrum velocity and spectrum velocity of the two records $(\xi=5 \%)$ (a) Pacoima Dam; (b) Rinaldi

from Figure 3 that pseudo spectrum velocity meets well with spectrum velocity for the short-middle period range, and the ratio of these two physical quantities distributes around 1.0. But together with the increment of the structural period, the ratio fluctuates obviously. As the site softens, the border of effective period becomes longer. Specifically, the turning point periods for soils of $S_{1}, S_{2}$ and $S_{3}$ are respectively $2.4 \mathrm{~s}, 2.8 \mathrm{~s}$ and $4.0 \mathrm{~s}$. And the existence of the above effective period range can partly explain the illogical rapid increment of spectrum displacement transferred from spectrum acceleration for long period structure.

In accordance with the method recommended in this paper from equations (2) (4), Figure 4 gives out the energy equivalent velocity spectrum, which is compatible with the design acceleration spectrum of GB50011-2001 Code and UBC97 Code. It can be seen that energy demand increases as the soil softens, and it increases also with the decline of fault distance, which is in consistence with the character drawn from actual records. At the same time, it should also be figured out that since the effective period range is different, which is $0 \sim 2.4 \mathrm{~s}$ for site soil of $S_{1}, 0 \sim 2.8 \mathrm{~s}$ for site soil of $S_{2}$ and $0 \sim 4.0 \mathrm{~s}$ for site soil of $S_{3}$, respectively, so the energy equivalent velocity value beyond these range are meaningless. Therefore, the discussion in this paper was limited in the above defined period scope.
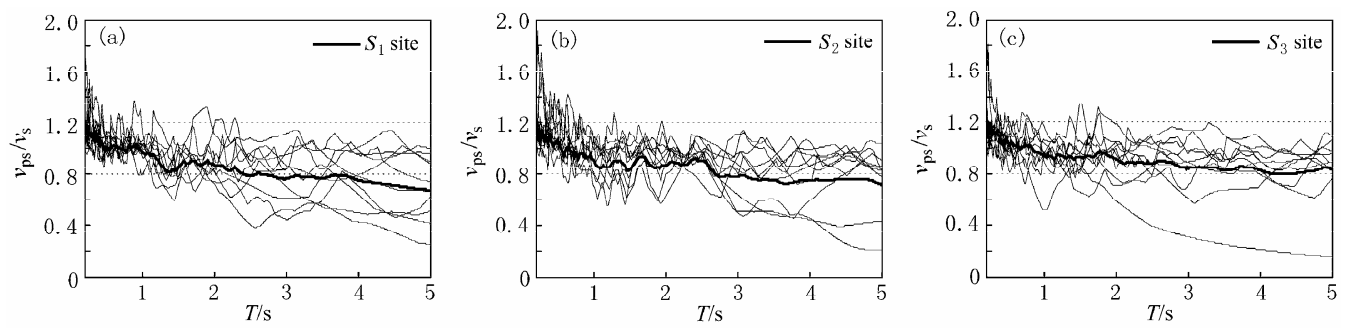

Figure 3 Ratio of pseudo spectrum velocity over spectrum velocity for different soil types $(\xi=5 \%)$ (a) Site soil of $S_{1}$; (b) Site soil of $S_{2}$; (c) Site soil of $S_{3}$

\section{Test of the acceleration spectra from seismic codes by energy bal- ance concept}

On collection of strong ground motion records throughout the world, an energy input design spectrum (EIDS) applicable to distance of $0 \sim 15 \mathrm{~km}$ from fault and peak ground acceleration $a_{\mathrm{pg}}=0.4$ 

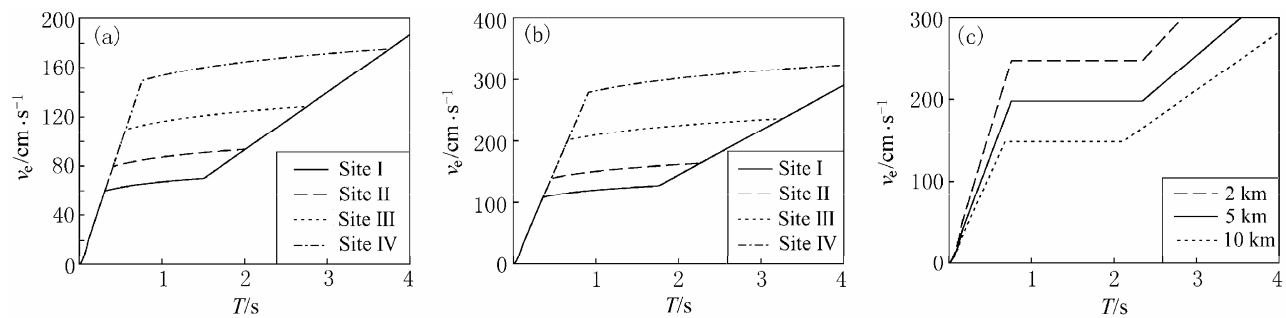

Figure 4 Energy input equivalent velocity spectrum compatible with the design acceleration spectrum of GB50011-2001 as well as UBC97 Code

(a) corresponds to GB50011-2001 Code under seldom occurred earthquake with fortification intensity of 8 degree; (b) corresponds to GB50011-2001 Code under seldom occurred earthquake with fortification intensity of 9 degree; (c) corresponds to UBC97 Code under site soil of $\mathrm{S}_{\mathrm{C}}$ in zone 4

$\mathrm{g}\left(\mathrm{g}=9.8 \mathrm{~m} / \mathrm{s}^{2}\right)$ was advised with the semi-theory and semi-empirical method (JIANG and ZHU, 2006). The design parameters such as turning-point period and platform height were determined according to the types of site soil $\left(S_{1}, S_{2}, S_{3}\right)$ and fault distances $(0 \sim 5 \mathrm{~km}, 5 \sim 10 \mathrm{~km}, 10 \sim 15 \mathrm{~km})$. Figure 5 describes the contrast of the proposed energy input design spectrum (EIDS) and energy equivalent velocity spectrum from ground records for site soil of $S_{1}, S_{2}$ with different fault distances. A high enough credibility could be guaranteed (JIANG and ZHU, 2006), and thus the energy design spectrum can be used for representation of actual energy demand of earthquakes close to faults. Based on the advised EIDS, an energy test was conducted for China's current code for seismic design of buildings (GB50011-2001) and UBC97 Code of USA, for the aim of discussing whether they are applicable to the seismic design of structures in near-fault regions.
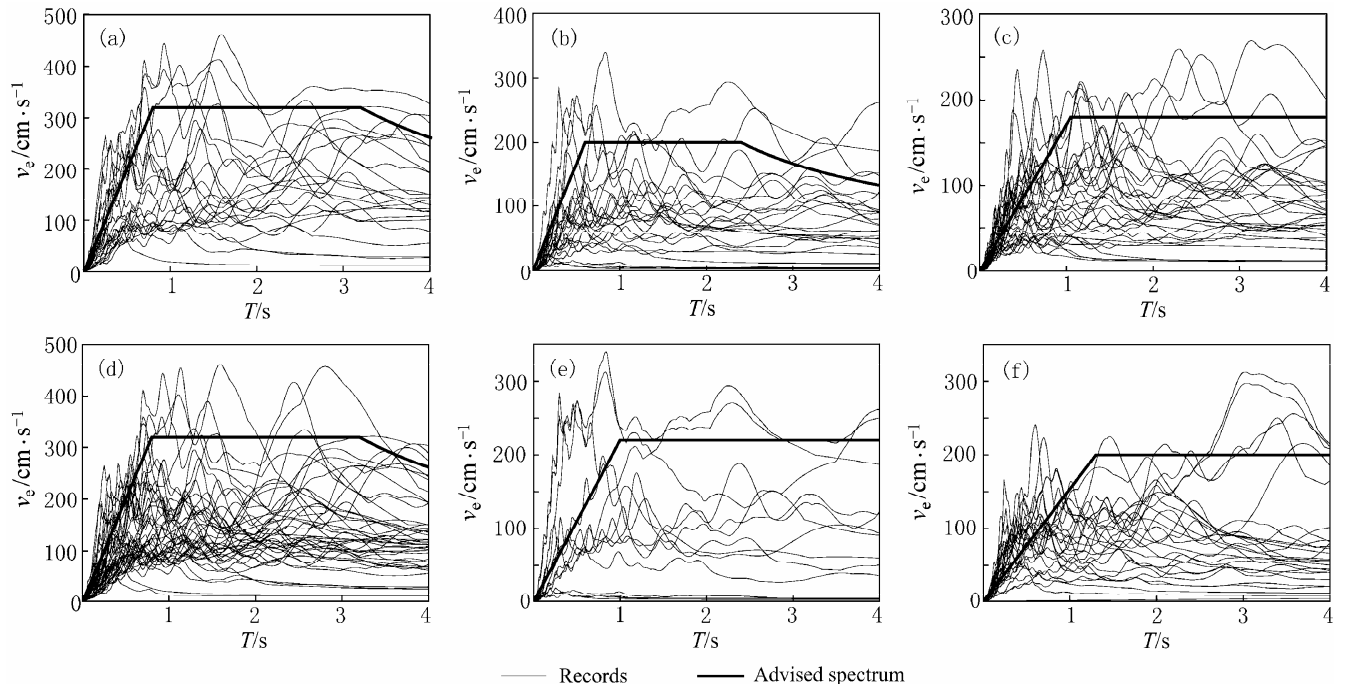

Figure 5 Comparison between advised energy input design spectrum and computation value from earthquake records

(a), (b), (c) are for fault distance of 0 5 km, 5 10 km and 10 15 km under site soil of $S_{1}$, respectively; (d),

(e), (f) are for fault distance of $0 \sim 5 \mathrm{~km}, 5 \sim 10 \mathrm{~km}$ and $10 \sim 15 \mathrm{~km}$ under site soil of $S_{2}$, respectively

Since the classification methods of site soil from the codes of USA (such as NEHRP, UBC97) are different from the codes of China (such as GB50011-2001), the average velocity of shear wave 
in site soil below $30 \mathrm{~m}$ from ground surface is used as the classification indicator for the former; the average velocity of shear wave in site soil below $20 \mathrm{~m}$ from ground surface and the thickness of covering soil with shear wave velocity larger than $500 \mathrm{~m} / \mathrm{s}$ are taken as dual indicators for Chinese codes. Comparison of the soil classification indicators by exploration test data (LÜ, ZHAO, 2007) shows the site soil of I of China covers site soil of $A, B$ and a part of site soil of $C$ of USA, site soil of II is between site soil of $C$ and $D$, site soil of III is between site soil of $D$ and $E$, and site soil of IV of China is under site soil of E of USA. Therefore, based on the classification principle mentioned above for earthquake records, the site soil of I of GB50011-2001 Code and $\mathrm{S}_{A}, \mathrm{~S}_{B}$ of UBC97 Code correspond to $S_{1}$; the site soil of II, III and $\mathrm{S}_{C}, \mathrm{~S}_{D}$ correspond to $S_{2}$; the site soil of IV and $\mathrm{S}_{E}$ correspond to $S_{3}$ in this paper.

For seldom occurred earthquake with intensity of 8 and 9 degree, as well as frequently occurred earthquake with intensity of 9 degree, the equivalent energy compatible with acceleration design spectrum for site soil of I of GB50011-2001 Code is obviously less than the proposed energy spectrum (EIDS) for site soil of $S_{1}$ of each fault distance, which means the GB50011-2001 Code underestimates the seismic demand of near-fault pulse in this region (Figure 6a). For of II of GB50011-2001 Code, under seldom occurred earthquake with intensity of 9 degree, the equivalent energy demand is close to the proposed spectrum for site soil of $S_{2}$ with fault distance of 10 15 $\mathrm{km}$. But there exists an apparent underestimation of actual energy for seldom occurred earthquake with intensity of 8 degree and frequently occurred earthquake with intensity of 9 degree (Figure 6b) in the effective period range of $0 \sim 2.8 \mathrm{~s}$. With the softening of the site soil, it can be seen from Figure $6 \mathrm{c}$ and Figure $6 \mathrm{~d}$ that the equivalent energy of site soil of III and IV under seldom occurred earthquake with intensity of 9 degree from GB50011-2001 Code is close to the proposed energy design spectrum of site soil of $S_{2}$ and $S_{3}$ under fault distance of $5 \sim 10 \mathrm{~km}$, which illustrates the code spectrum could consider the energy demand under this case. However, the equivalent energy is obviously lower than the design spectrum under fault distance of $0 \sim 5 \mathrm{~km}$, especially for seldom occurred earthquake with intensity of 8 degree and frequently occurred earthquake with intensity of 9 degree, therefore it can not be effectively applied to seismic design within this scope.

In general, spectrum test shows that GB50011-2001 Code can just match the energy supply effect of near-fault to a certain extent only under seldom occurred earthquake with intensity of 9 degree for soil II, III, IV and far away from distance of $5 \mathrm{~km}$ from fault, which indicates the impact of fling or pulse effect is not embodied suitably from the height of platform of the current code acceleration spectrum curves.

For site soil of $S_{A}$ of UBC97 Code, although the near-fault factor $N_{a}$ and $N_{v}$ was introduced, the equivalent energy is still less than the proposed design spectrum of site soil of $S_{1}$ (Figure 6e). The perhaps reason is, according to UBC97 Code, the weight proportion of $N_{a}$ and $N_{v}$ for $S_{A}$ is the smallest among all the types of site soil, and at the same time the database of this paper includes the main records from the 1999 Chi-Chi earthquake, which is void for UBC97 Code. For site soil of $S_{B}, S_{C}$ and $S_{D}$ of UBC97 Code, the equivalent energy for fault distance of $2 \mathrm{~km}, 5 \mathrm{~km}$ and 10 $\mathrm{km}$ is very close to the corresponded EIDS under the distance of $0 \sim 5 \mathrm{~km}, 5 \sim 10 \mathrm{~km}$ and $10 \sim 15 \mathrm{~km}$ (Figures 6f, 6g, 6h). For site soil of $S_{E}$ of UBC97 Code, the platform value of equivalent energy spectrum for fault distance of $2 \mathrm{~km}, 5 \mathrm{~km}$ is even a little higher than the EIDS under the fault distance of $0 \sim 5 \mathrm{~km}$ and $5 \sim 10 \mathrm{~km}$, respectively (Figure 6i). And the equivalent energy for fault distance of $10 \mathrm{~km}$ is very close to the corresponded EIDS under the distance of $10 \sim 15 \mathrm{~km}$.

Generally, by the comparison between Figures $6 \mathrm{a} \sim 6 \mathrm{~d}$ and Figures $6 \mathrm{e} \sim 6 \mathrm{i}$, it can be seen that since the UBC97 Code takes into account the near-fault effects by the introduction of $N_{a}$ and $N_{v}$, 

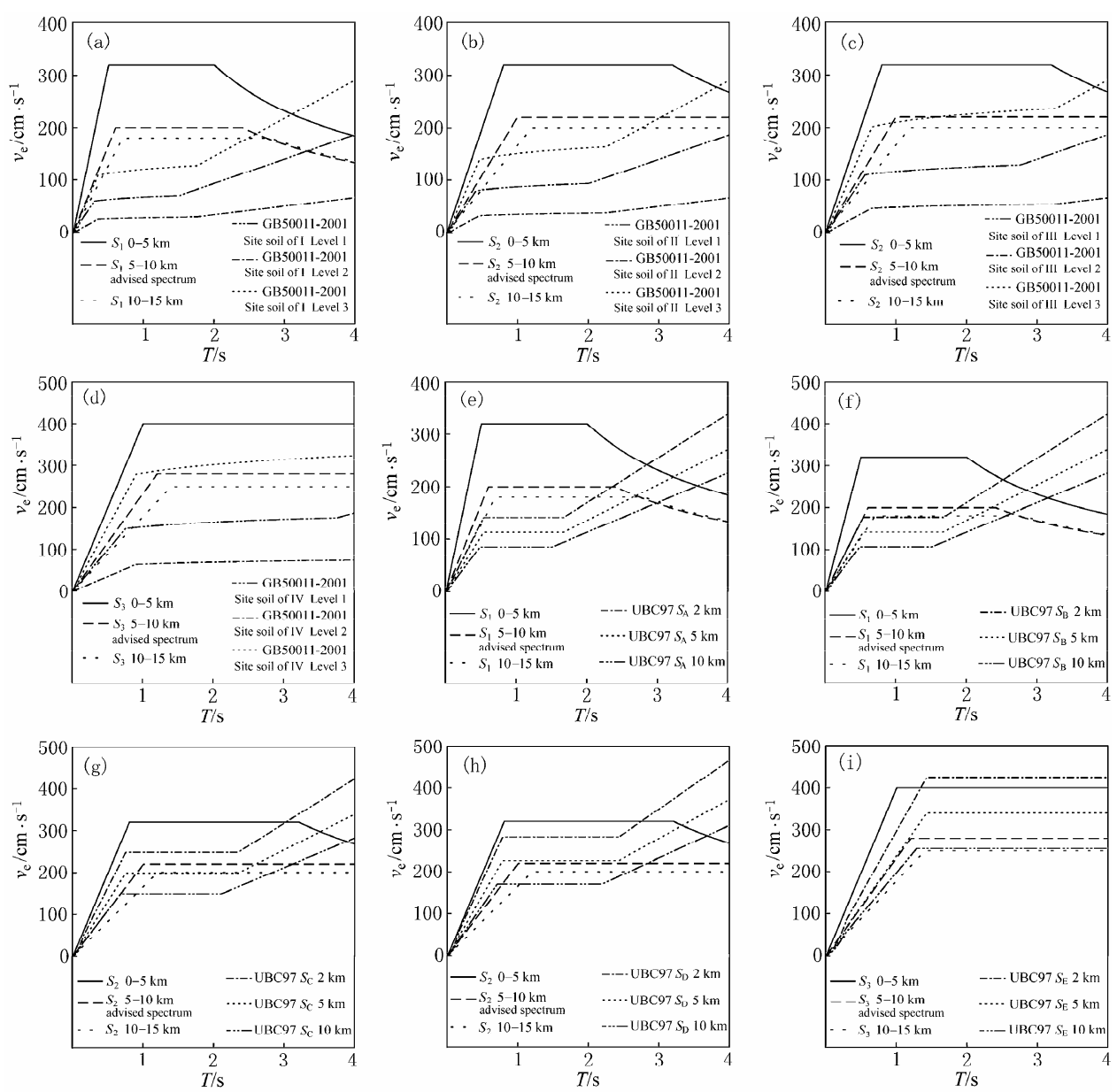

Figure 6 Comparison between advised EIDS and equivalent energy spectrum from GB50011-2001 as well as UBC97 Code

(a) is between EIDS for site soil of $S_{1}$ and I of GB, (b) is between EIDS for site soil of $S_{2}$ and II of GB; (c) is between EIDS for site soil of $S_{2}$ and III of GB; (d) is between EIDS for site soil of $S_{3}$ and IV of GB; (e) is between EIDS for site soil of $S_{1}$ and $\mathrm{S}_{\mathrm{A}}$ of UBC97; (f) is between EIDS for site soil of $S_{1}$ and $\mathrm{S}_{\mathrm{B}}$ of UBC97; (g) is between EIDS for site soil of $S_{2}$ and $\mathrm{S}_{\mathrm{C}}$ of UBC97; (h) is between EIDS for site soil of $S_{2}$ and $\mathrm{S}_{\mathrm{D}}$ of UBC97; (i) is between EIDS for site soil of $S_{3}$ and $S_{E}$ of UBC97. Level 1: seldom occurred earthquake with fortification intensity of 8 degree; Level 2 : frequently occurred earthquake with fortification intensity of 9 degree; Level 3: seldom occurred earthquake with fortification intensity of 9 degree

the control parameters such as the height and width of platform, as well as the control period of turning-point are more reasonable than GB50011-2001 Code. The UBC97 Code can effectively reflect the energy supply of near-fault ground motion except for site soil of $S_{\mathrm{A}}$, and some modification is needed for GB50011-2001 Code to be applicable to near-field regions. At the same time, the proposed energy input design spectrum (EIDS) can be proved to be reasonable by comparison with UBC97 Code.

\section{Conclusions}

Based on the above research, some conclusions can be drawn as follows:

1) Firstly, a simplified calculation method, for computing equivalent energy from code de- 
sign spectrum, was developed by introduction of spectrum velocity amplification factor. And based on near-fault records all around the world, the effective period extent for this formula was found to be $0 \sim 2.4 \mathrm{~s}, 0 \sim 2.8 \mathrm{~s}$ and $0 \sim 4.0 \mathrm{~s}$ for site soil of $S_{1}, S_{2}$ and $S_{3}$, respectively.

2) The contrast between the proposed energy input design spectrum (EIDS) applicable to $0 \sim 15 \mathrm{~km}$ fault zone and the spectrum compatible with seismic codes shows that, GB50011-2001 Code can just match the near-fault energy supply effect to a certain extent only under seldom occurred fortification earthquake with intensity of 9 degree for site soil of III and IV, which can not embody the impact of near-fault effect to structural damage for other condition. It is necessary to adjust the spectrum parameters in order to be applicable to near-fault regions.

3) On the contrary, it also shows that for distinct fault distance and site soil, the energy spectrum compatible with UBC97 Code can match well with actual energy demand of earthquakes close to active faults except site soil of $S_{\mathrm{A}}$. It means the near-fault factor $\left(N_{a}, N_{v}\right)$ by UBC97 Code is essential for structure design within $0 \sim 15 \mathrm{~km}$ fault region. And the proposed energy input design spectrum can be proved to be reasonable once again from the comparison with UBC97 Code.

It should be pointed out that, owing to the lack of near-fault records for the statistical database of the code for seismic design of buildings of China (GB50011-2001), so it did not take into account the near-fault effect, therefore the above conclusion is understandable. But with the enhancing of China's economic capability and the in-depth exploiture of the western region, substantial structures would be built inevitably across the faults, and then it is essential to amendment the earthquake fortification level by the way of specific code design spectrum.

Acknowledgements Great thanks for their valuable comments and suggestions from the referees.

\section{References}

Chou C C and Uang C M. 2000. Establishing absorbed energy spectra: An attenuation approach [J]. Earthquake Engineering and Structural Dynamics, 29: 1441-1 445.

European Committee for Standardization. 2003. Eurocode 8: Design of structures for earthquake resistance-Part 1: General rules, seismic actions and rules for buildings [S] (prEN 1998-1:2003). Brussels: Management Centre: rue de Stassart: 27.

GONG Mao-sheng, XIE Li-li, ZHANG Wen-bo. 2003. Attenuation of input energy of strong ground motion [J]. Earthquake Engineering and Engineering Vibration, 23(3): 15-24 (in Chinese).

Hudson D E. 1962. Some problems in the application of spectrum techniques to strong motion earthquake analysis [J]. Bull Seism Soc Amer, 52(2): 180-199.

International Council of Building Officials. 1997. 1997 Uniform Building Code [S]. Whittier, California: International Conference of Building Officials. Vo1.2: 34-35.

JIANG Hui and ZHU Xi. 2006. Energy input design spectra for near-fault regions and application in energy-based seismic design [J]. Earthquake Engineering and Engineering Vibration, 26(5): 102-108 (in Chinese)

JIANG Hui. 2007. Performance-based Seismic Design of Bridge Structure Excited by Near-fault Earthquake Using Energy Concept [D]: [Doctoral Dissertation]. Beijing: Beijing Jiaotong University: 77-81 (in Chinese).

LÜ Hong-shan and ZHAO Feng-xin. 2007. Site coefficients suitable to China site category [J]. Acta Seismologica Sinica, 29(1): 65-76 (in Chinese).

Ministry of Construction of the People's Republic of China. 2001. Code for Seismic Design of Buildings (GB50011-2001) [S]. Beijing: China Architecture \& Building Press: 16-18 (in Chinese).

NI Yong-jun. 2001. Design Earthquake and Displacement-based Seismic Design Method for Bridge Structures [D]: [Doctoral Dissertation]. Beijing: Northern Jiaotong University: 26-27 (in Chinese).

Somerville P G, Smith N F, Graves R W, et al. 1997. Modification of empirical strong ground motion attenuation relations to include amplitude and duration effects of rupture directivity [J]. Seism Res Lett, 68(1): 199-222.

Trifunac M D, and Brady A G. 1975. A study on the duration of strong earthquake ground motion [J]. Bull Seism Soc Amer, 65: 581-626. 